\title{
Fluorescence in situ hybridization karyotyping reveals the presence of two distinct genomes in the taxon Aegilops tauschii
}

\author{
Laibin Zhao ${ }^{1}$, Shunzong Ning ${ }^{1}$, Yingjin $\mathrm{Yi}^{1}$, Lianquan Zhang ${ }^{1}$, Zhongwei Yuan ${ }^{1}$, Jirui Wang ${ }^{1,2}$, Youliang Zheng ${ }^{1,2}$, \\ Ming Hao ${ }^{1 *}$ (D) and Dengcai Liu ${ }^{1,2^{*}}$
}

\begin{abstract}
Background: Aegilops tauschii is the donor of the bread wheat D genome. Based on spike morphology, the taxon has conventionally been subdivided into ssp. tauschii and ssp. strangulata. The present study was intended to address the poor match between this whole plant morphology-based subdivision and genetic relationships inferred from genotyping by fluorescence in situ hybridization karyotyping a set of 31 Ae. tauschii accessions.

Results: The distribution of sites hybridizing to the two probes oligo-pTa-535 and (CTT) 10 split the Ae. tauschii accessions into two clades, designated $D^{t}$ and $D^{s}$, which corresponded perfectly with a previously assembled phylogeny based on marker genotype. The $D^{t}$ cluster was populated exclusively by ssp. tauschii accessions, while the $D^{s}$ cluster harbored both ssp. strangulata and morphologically intermediate accessions. As a result, it is proposed that Ae. tauschii ssp. tauschii is restricted to carriers of the $D^{t}$ karyotype: their spikelets are regularly spaced along the rachis, at least in the central portion of their spike. Accessions classified as Ae. tauschii ssp. strangulata carry the $D^{s}$ karyotype; their spikelets are irregularly spaced. Based on this criterion, forms formerly classified as ssp. tauschii var. meyeri have been re-designated ssp. strangulata var. meyeri.

Conclusions: According to the reworking of the taxon, the bread wheat D genome was most probably donated by ssp. strangulata var. meyeri. Chromosomal differentiation reveals intra-species taxon of Ae. tauschii. Ae. tauschii ssp. tauschii has more distant relationship with breed wheat than ssp. strangulata and can be used for breeding improving effectively.
\end{abstract}

Keywords: Chromosome differentiation, D genome, Repeat sequences, Spike morphology, Subspecies, Wheat evolution

\section{Background}

The range of diploid goatgrass (Aegilops tauschii) stretches from Turkey in the west to China in the east. The species is adapted to a wide diversity of environments [1]. Most significantly, it is understood to be the donor of the bread wheat $\mathrm{D}$ genome [2,3], as well as being a pivotal genome in several Aegilops tetraploid and hexaploid species [4]. Based on variation in spike morphology, the species has conventionally been subdivided into ssp. tauschii and ssp. strangulata; members of

\footnotetext{
* Correspondence: haomingluo@foxmail.com; dcliu7@yahoo.com

${ }^{1}$ Triticeae Research Institute, Sichuan Agricultural University, No. 211 Huiming Rd, Wenjiang District, Chengdu City, Sichuan province 611130, People's Republic of China

Full list of author information is available at the end of the article
}

the former subspecies develop elongated cylindrical spikelets, while those of the latter form moniliform spikes bearing quadrate spikelets [5-8]. Within ssp. tauschii two distinct varieties have been recognized, namely var. anathera and var. meyeri. The diagnostic character for the former variety is awnlessness, while the latter types form slender, short spikes and develop only 4-8 spikelets per spike [5, 8]. This classification remains controversial because of the existence of morphologically intermediate types [1,9-11]. For example, individuals forming mildly moniliform spikes have been classified as ssp. strangulata, even though this taxon is restricted to individuals which form a sharply defined moniliform spike $[10,12]$. 
The established subspecies structure is not well matched with genetic relationships derived from genotypic characterization. Two distinct phylogenetic lineages, designated L1 and L2, have been recognized [13-15]. The former coincides with ssp. tauschii [13], but the latter includes, along with ssp. strangulata, accessions formerly assigned to ssp. tauschii $[13,15,16]$. The most troublesome taxon is var. meyeri, which has been assigned to ssp. tauschii on the basis of spike morphology [11] but appears to be genetically more closely related to ssp. strangulata [13, 16-18].

Much of the large (4 Gbp) Ae. tauschii genome consists of repetitive DNA [19-22]. When C-banding was exploited for karyotypic analysis, the conclusion was that the bread wheat D genome was more similar to the one present in ssp. strangulata than the one in ssp. tauschii $[23,24]$. A more sophisticated karyotyping tool is represented by fluorescence in situ hybridization (FISH), and this approach has been applied with great success to identify individual wheat chromosomes, based on the distribution of sites of hybridization with probes designed to detect a number of repetitive sequences [25-31]. Here, the purpose was to use FISH to enable an objective, karyotype-based analysis of the subspecies structure of Ae. tauschii.

\section{Methods}

\section{Plant materials}

The bread wheat cultivar Chinese Spring (CS) and a collection of 31 Ae. tauschii accessions (Table 1) were subjected to FISH karyotyping. The spike morphology of the Ae. tauschii accessions was observed more than ten years at Wenjiang, Dujiangyan and Yaan experimental station of Sichuan Agricultural University. Given the existence of mildly moniliform spike types, an objective criterion, termed the subspecies index (SI), was also used to score spike morphology: the SI represents the ratio between the widths of the glume and the rachis segment measured on a spikelet sampled from the central portion of the spike. Individuals classified as ssp. tauschii have a low SI, while those belonging to ssp. strangulata have a high SI [32, 33]. Here, the measurement points for spikelet glume width $(\mathrm{G})$ and rachis segment width (R) used to derive SI are indicated in Fig. 1. We measured the glume width in side face rather than in front face [32]. The mean SI obtained from about ten spikelets was used. Because the spikes morphology of each accession from the three different geographical fields were no obvious variation, only the spikes collected from Wenjiang experimental station were used to analyze. Least significant difference (LSD) was used for mean comparison at the probability of $P<0.01$ by SPSS V20 (International Business Machines Corp., NY, USA).

\section{FISH karyotyping}

Caryopses were imbibed for $24 \mathrm{~h}$ at $4{ }^{\circ} \mathrm{C}$, then germinated under a $16 \mathrm{~h}$ photoperiod (light/dark temperature $22 / 16{ }^{\circ} \mathrm{C}$ ). Root tips of length $1-2 \mathrm{~cm}$ were excised and exposed for $2 \mathrm{~h}$ to $1.0 \mathrm{MPa} \mathrm{NO}$ gas, fixed in glacial acetic acid for at least $5 \mathrm{~min}$, and finally stored in $70 \% \mathrm{v} /$ $\mathrm{v}$ ethanol before preparing slides. The slides were prepared as previously described by Komuro et al. [30] and then denaturated as described by Hao et al. [34]. A $10 \mu \mathrm{L}$ aliquot of hybridization mixture was applied to each slide, which was allowed to incubate at $37{ }^{\circ} \mathrm{C}$ for least one hour. Finally, a drop of DAPI-containing Vectashield mounting medium (Vector Laboratories, Inc., Burlingame, CA, USA) was added and the preparation was covered with a coverslip. Hybridization signals were observed using an Olympus BX-51 epifluorescence microscope and the images were taken using a Photometric SenSys Olympus DP70 CCD camera (Olympus, Tokyo). Raw images were processed using Photoshop V7.0 (Adobe Systems Incorporated, San Jose, CA). Once the slide had been scored, it was readied for a subsequent stripping and rehybridization following Komuro et al. [30]. The probes included in the hybridization solution were 6-carboxyfluorescein (6-FAM) or 6-carboxytetramethylrhodamine (Tamra) labeled oligonucleotides $(\mathrm{CTT})_{10},(\mathrm{AAC})_{5}$ and $(\mathrm{ACG})_{5}[28,35,36]$, oligopSc119.2, oligo-pTa-535, oligo-pTa71 [31] and oligo-pTa-713 [37], all synthesized by TSINGKE Biological Technology Company (Chengdu, Sichuan, China).

\section{Results}

\section{The spike morphology of Ae. tauschii}

Based on the appearance of the spike, the 31 Ae. tauschii accessions were classified into three morphological types (Table 1; Fig. 1) as follows:

Type S (ten accessions): these accessions formed markedly moniliform spikes with quadrate spikelets (similar with respect to width and length). Their average SI values ranged from 1.66-1.85 in 2015 in Wenjiang. Individual spikelets of these accessions ranged from 1.522.13. The members of this group all belong to ssp. strangulata.

Type $\mathrm{T}$ (nine accessions): these accessions formed elongated cylindrical spikes. Their low SI (1.04-1.27) reflected the similar width of their spikelet glume and rachis segment. Individual spikelets of these accessions ranged from 1.00-1.36. The members of this group all belong to ssp. tauschii.

Type I (12 accessions): these accessions were classified as intermediate types, with an SI ranging from 1.40-1.74. Individual spikelets of these accessions ranged from 1.33-2.09. Some (PI603238, PI574465, PI431602, PI603249 and AL8/78) had previously been assigned to ssp. strangulata on the basis of their mildly moniliform spike, but their spikelets were too elongated to be 
Table 1 Aegilops tauschii accessions

\begin{tabular}{|c|c|c|c|c|c|c|c|}
\hline Code & Accession $^{a}$ & Origin & Collector's taxon & Spike type $(\mathrm{SI} \pm \mathrm{SD})^{\mathrm{b}}$ & FISH group & Our taxon & Sublineage ${ }^{c}$ \\
\hline 1 & AS2388 & Iran & ssp. strangulata & $\mathrm{S}(1.72 \pm 0.10)^{\mathrm{ABCD}}$ & $D^{5}$ & ssp. strangulata & L2E \\
\hline 2 & PI603227 & Iran & ssp. strangulata & $S(1.59 \pm 0.07)^{\mathrm{EF}}$ & $D^{5}$ & ssp. strangulata & L2E \\
\hline 3 & Clae13 & Iran & ssp. strangulata & $S(1.69 \pm 0.09)^{B C D E}$ & $D^{s}$ & ssp. strangulata & L2E \\
\hline 4 & Clae16 & Iran & ssp. strangulata & $\mathrm{S}(1.73 \pm 0.11)^{\mathrm{ABC}}$ & $D^{5}$ & ssp. strangulata & L2E \\
\hline 5 & Clae18 & Iran & ssp. strangulata & $S(1.74 \pm 0.10)^{A B C}$ & $D^{5}$ & ssp. strangulata & L2E \\
\hline 6 & AS2386 & Iran & ssp. strangulata & $\mathrm{S}(1.85 \pm 0.14)^{\mathrm{A}}$ & $D^{5}$ & ssp. strangulata & - \\
\hline 7 & AS2403 & unknown & ssp. strangulata & $\mathrm{S}(1.79 \pm 0.08)^{\mathrm{AB}}$ & $D^{s}$ & ssp. strangulata & L2E \\
\hline 8 & AS2405 & Iran & ssp. strangulata & $S(1.77 \pm 0.04)^{A B C}$ & $D^{5}$ & ssp. strangulata & L2E \\
\hline 9 & AS2402 & Israel & ssp. strangulata & $S(1.66 \pm 0.07)^{\mathrm{CDE}}$ & $D^{5}$ & ssp. strangulata & L2E \\
\hline 10 & AS66 & Transcaucasia & ssp. strangulata & $S(1.76 \pm 0.09)^{A B C}$ & $D^{5}$ & ssp. strangulata & L2E \\
\hline 11 & PI603238 & Azerbaijan & ssp. strangulata & I $(1.40 \pm 0.04)^{G}$ & $D^{s}$ & ssp. strangulata & L2 W \\
\hline 12 & PI574465 & Azerbaijan & ssp. strangulata & I $(1.46 \pm 0.09)^{G}$ & $D^{5}$ & ssp. strangulata & L2 W \\
\hline 13 & PI431602 & Turkmenistan & ssp. strangulata & I $(1.41 \pm 0.07)^{\mathrm{FG}}$ & $D^{s}$ & ssp. strangulata & L2 W \\
\hline 14 & PI603249 & Iran & ssp. strangulata & I $(1.60 \pm 0.05)^{\mathrm{EF}}$ & $D^{s}$ & ssp. strangulata & L2 W \\
\hline 15 & AL8/78 & Armenia & ssp. strangulata & I $(1.41 \pm 0.05)^{G}$ & $D^{5}$ & ssp. strangulata & L2 W \\
\hline 16 & PI603239 & Azerbaijan & ssp. tauschii & I $(1.67 \pm 0.12)^{B C D E}$ & $D^{s}$ & ssp. strangulata & L2 W \\
\hline 17 & PI603233 & Azerbaijan & ssp. tauschii & I $(1.41 \pm 0.07)^{G}$ & $D^{s}$ & ssp. strangulata & L2 W \\
\hline 18 & PI276985 & Iran & ssp. tauschii var. meyeri & I $(1.74 \pm 0.20)^{\mathrm{ABC}}$ & $D^{5}$ & ssp. strangulata var. meyeri & L2E \\
\hline 19 & Clae26 & Iran & ssp. tauschii var. typica & I $(1.46 \pm 0.05)^{G}$ & $D^{5}$ & ssp. strangulata & L2E \\
\hline 20 & AS63 & unknown & ssp. tauschii var. meyeri & I $(1.49 \pm 0.07)^{\mathrm{FG}}$ & $D^{5}$ & ssp. strangulata var. meyeri & L2E \\
\hline 21 & Clae23 & Iran & ssp. tauschii var. meyeri & I $(1.59 \pm 0.04)^{\mathrm{EF}}$ & $D^{5}$ & ssp. strangulata var. meyeri & L2E \\
\hline 22 & Clae21 & Iran & ssp. tauschii var. typica & I $(1.70 \pm 0.07)^{B C D E}$ & $D^{5}$ & ssp. strangulata & L2E \\
\hline 23 & PI210987 & Afghanistan & ssp. tauschii & $\mathrm{T}(1.18 \pm 0.03)^{\mathrm{H}}$ & $D^{t}$ & ssp. tauschii & L1E \\
\hline 24 & PI574467 & Russian Federation & ssp. tauschii & $\mathrm{T}(1.04 \pm 0.04)^{1}$ & $D^{t}$ & ssp. tauschii & L1 W \\
\hline 25 & AS79 & China & ssp. tauschii & $\mathrm{T}(1.21 \pm 0.03)^{\mathrm{H}}$ & $D^{t}$ & ssp. tauschii & L1E \\
\hline 26 & AS77 & China & ssp. tauschii & $\mathrm{T}(1.18 \pm 0.03)^{\mathrm{H}}$ & $D^{t}$ & ssp. tauschii & - \\
\hline 27 & AS2410 & China & ssp. tauschii & $\mathrm{T}(1.19 \pm 0.04)^{\mathrm{H}}$ & $D^{t}$ & ssp. tauschii & - \\
\hline 28 & AS60 & Iran & ssp. tauschii & $\mathrm{T}(1.22 \pm 0.05)^{\mathrm{H}}$ & $D^{t}$ & ssp. tauschii & L1E \\
\hline 29 & AS67 & Iran & ssp. tauschii & $\mathrm{T}(1.27 \pm 0.04)^{\mathrm{H}}$ & $D^{t}$ & ssp. tauschii & L1E \\
\hline 30 & AS68 & Iran & ssp. tauschii & $\mathrm{T}(1.25 \pm 0.09)^{\mathrm{H}}$ & $D^{t}$ & ssp. tauschii & L1E \\
\hline 31 & Clae1 & Pakistan & ssp. tauschii & $\mathrm{T}(1.17 \pm 0.04)^{\mathrm{H}}$ & $D^{t}$ & ssp. tauschii & L1E \\
\hline
\end{tabular}

a: Accessions marked "AS" were obtained from the Triticeae Research Institute, Sichuan Agricultural University, China; those marked "Pl" or "Clae" were obtained from USDA-ARS. ${ }^{\text {b}}$ : Types S (ssp. strangulata), T (ssp. tauschii) and I (intermediate forms). The SI was given by the ratio spikelet glume width/rachis segment width. Capital letters after the average SI value and standard deviations (SD) denote the results of LSD comparison $(P<0.01)$. ${ }^{\complement}$ : Genetic lineage data according to marker genotype taken from Wang et al. (2013). L1E (L1 East) and L1 W (L1 West) represent the T type gene pool, and L2E (L2 East) and L2 W (L2 West) the S type gene pool

unequivocally assigned to this taxon. Accessions PI276985, AS63 and CIae23 (assigned previously to ssp. tauschii var. meyeri) formed elongated spikelets, but their spikes were not sufficiently cylindrical and their rachis segments too narrow to fit this taxon.

\section{FISH markers specific for two typical ssp.}

Seven probes (Fig. 2) were preliminarily hybridized in situ to mitotic chromosome spreads of nine accessions, including the two from S type (AS2388 and AS2402), two from I type (AS63 and PI431602), and five from $\mathrm{T}$ type (AS68, AS77, AS79, CIae1 and PI210987). However, the probes oligo-pTa-713, $(\mathrm{AAC})_{5}$ and $(\mathrm{ACG})_{5}$ failed to reveal any subspeciesspecific difference for the analyzed materials. As a result, these three probes were not used any further. Although oligo-pSc119.2 also failed to detect subspeciesspecific difference, it was helpful to identify chromosomes 2D, 3D, and 4D. Oligo-pSc119.2 and the remaining three probes were tested on mitotic chromosome spreads of the full set of Ae. tauschii accessions as well as on CS. 


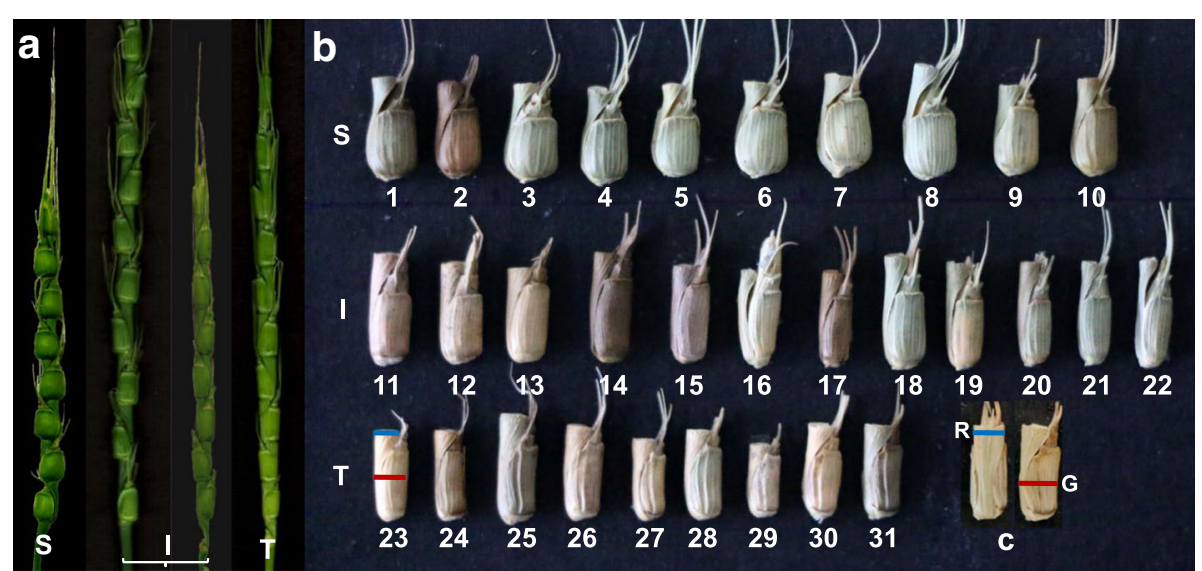

Fig. 1 Morphological variation within Ae. tauschii. (a) Spikes, (b, c) spikelets. Types S (ssp. strangulata), T (ssp. tauschii) and I (intermediate forms) are distinguished by the width of the rachis segment (blue bar in \#23) and the glume (red bar in \#23). In (c) the measurement points for spikelet glume width (G) and rachis segment width (R) used to derive SI are indicated. The numbers 1-31 in (b) relate to accessions 1-31 in Table 1

\section{Oligo-pTa71}

This sequence hybridized to the nucleolar organizing region on chromosome arm 5DS in all of the $A e$. tauschii accessions. The hybridization signal strength was higher in the Type $\mathrm{T}$ than in the Type $\mathrm{S}$ accessions (Fig. 3). However, the probe did not hybridize strongly with the CS 5D chromosome.

\section{Oligo-pSc119.2}

This probe hybridized to sites close to the telomere of chromosome arms 1DS, 2DS, 3DS and 4DS (Fig. 4). The pattern of hybridization did not discriminate between the Types S, T and I, but was useful as a means of identifying individual chromosomes.
$(\mathrm{CTT})_{10}$

This probe hybridized to sites on chromosome arms 1DS, 2DS, 3DS and 4DS, and the patterns were informative with respect to the three Types (Fig. 3). The four chromosome arms harbored a hybridization site in all Type $\mathrm{S}$ accessions, but these sites were absent from all Type $\mathrm{T}$ accession karyotypes. A site in the sub-telomeric region of chromosome arm 1DL was present in both the Type T accessions AS67 and AS68 (from Iran) and Clae1 (Pakistan). A further site in the sub-telomeric region of chromosome arm 2DS was restricted to just three Type T accessions (AS77, AS79, AS2410) all originating from central China, the most easterly reach of the species.

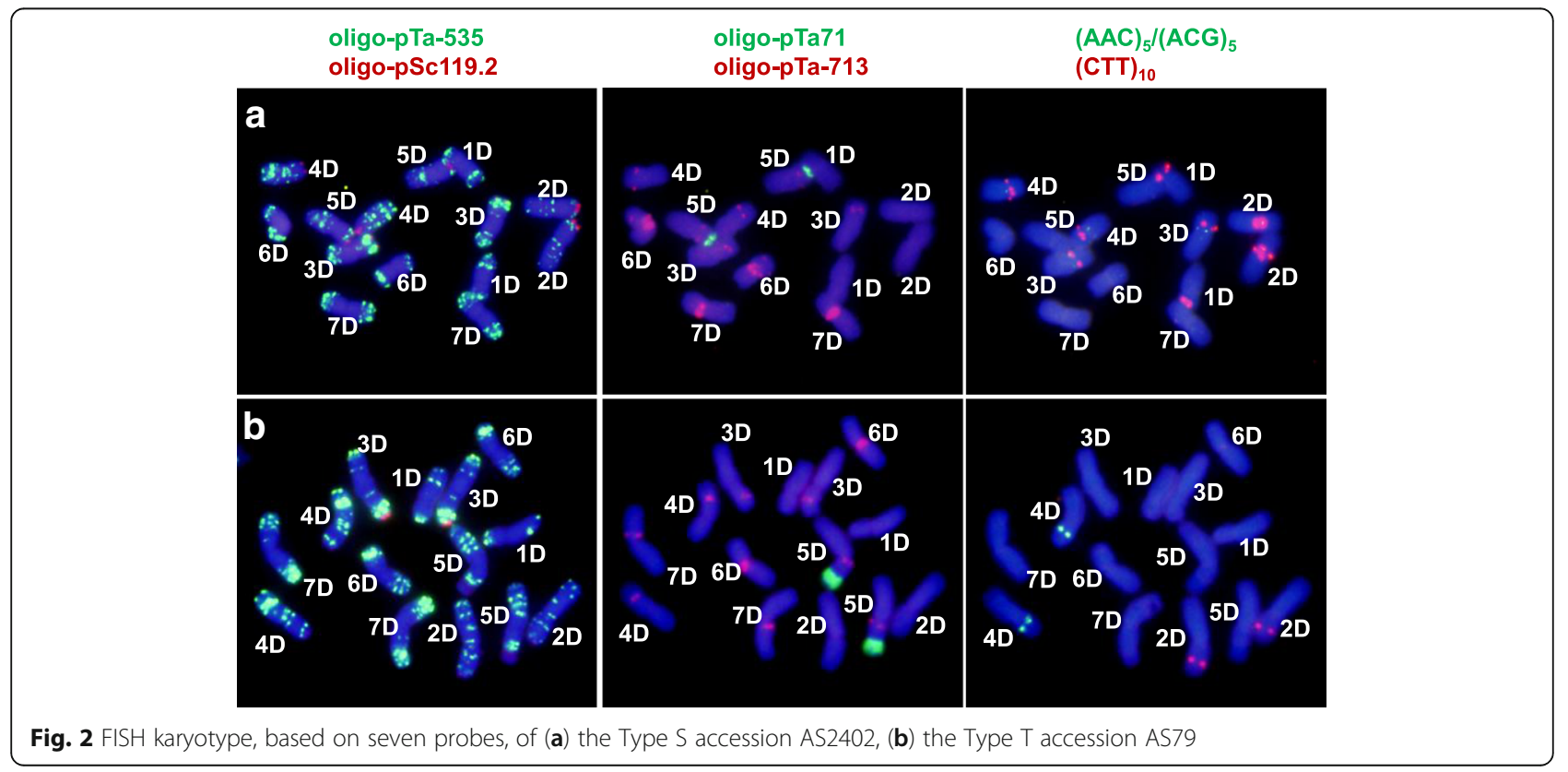




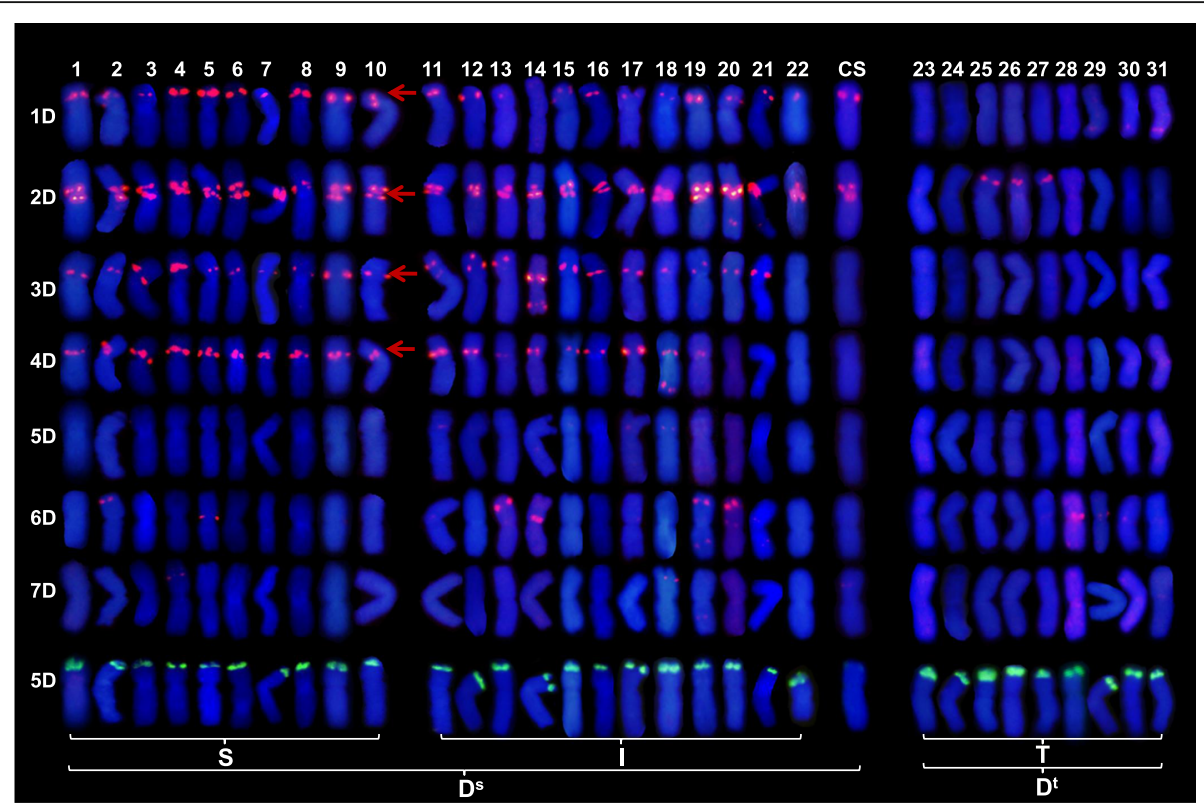

Fig. 3 FISH karyotyping of 31 accessions of Ae. tauschii and the D genome of CS, derived from hybridization with (CTT) 10 (red) and oligo-pTa71 (green). Type S: ssp. strangulata, Type T: ssp. tauschii, Type I: intermediate forms. Sites specific for Type S chromosomes are shown by red arrows. The numbers 1-31 in (b) relate to accessions 1-31 in Table 1

\section{Oligo-pTa-535}

The oligo-pTa-535 probe hybridized to many chromosomal sites, allowing it to be used as a means discriminating each of the seven of Ae. tauschii chromosomes (Fig. 4). Type-specific sites were observed on chromosome arms 2DS, 3DL, 4DS, 5DL and 6DL. Both the middle region of chromosome arm 2DS and the subtelomeric region of chromosome arm 4DS included hybridization sites which were unique to Type $\mathrm{T}$ accessions, while one site in the sub-telomeric region of chromosome arm 3DL and another in the centromeric region of 5DL were absent from all Type $\mathrm{T}$ accessions. The 5DL arm harbored several hybridization sites, but their distribution along the arm differed between Type $\mathrm{S}$ and Type $\mathrm{T}$ accessions. A similar Type-specific distribution of sites was detected in the region stretching from

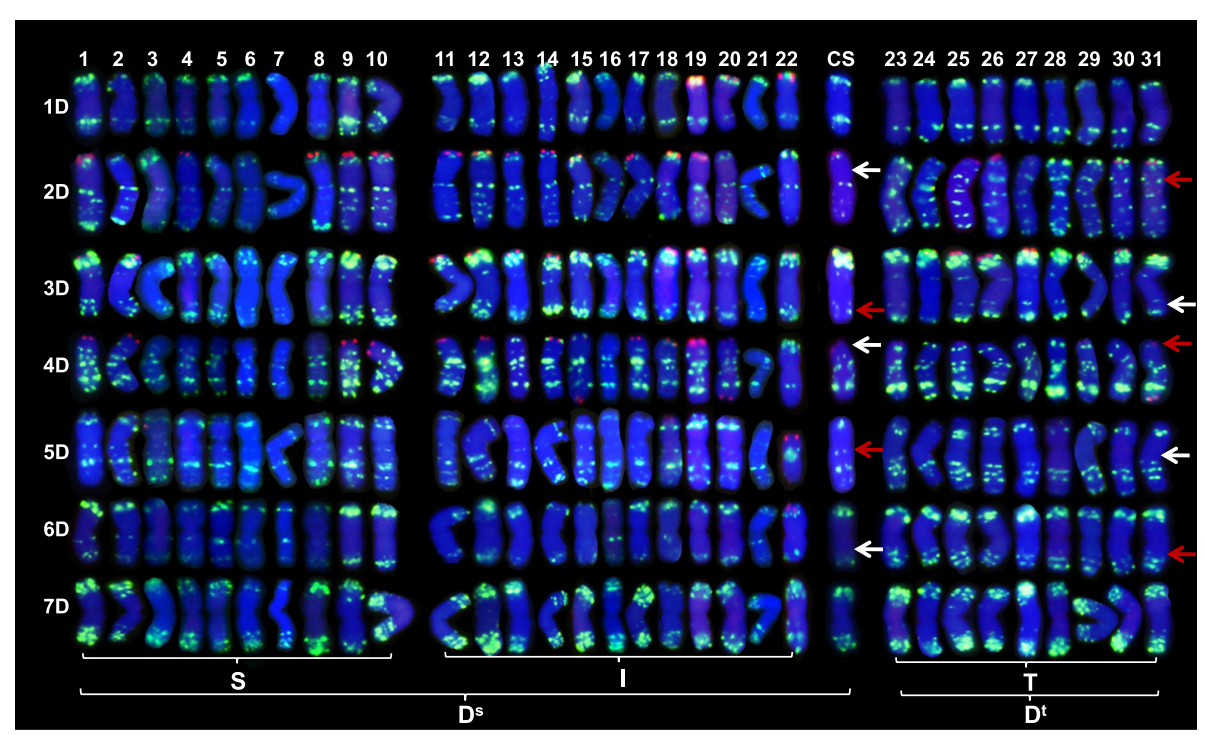

Fig. 4 FISH karyotyping of 31 accessions of Ae. tauschii and the D genome of CS, derived from hybridization with oligo-pSc1 19.2 (red) and oligo-pTa-535 (green). Type S: ssp. strangulata, Type T: ssp. tauschii, Type I: intermediate forms. The white arrows indicate sites which are absent, and the red arrows sites which are present for FISH signals. The numbers 1-31 in (b) relate to accessions 1-31 in Table 1 
about two thirds of the way along chromosome arm $6 \mathrm{DL}$ to its telomere.

\section{The FISH karyotype of type $\mathrm{S}$ and type I accessions}

The karyotypes of Type $S$ and Type I accessions were quite similar to one another. The four $(\mathrm{CTT})_{10}$ sites present in all Type $\mathrm{S}$ (but in no Type $\mathrm{T}$ ) accessions were represented in most of the Type I karyotypes; the exceptions were the chromosome arm 1DS site (missing in PI603249), the 3DS site (missing in PI603249 and Clae21) and the 4DS site (missing in Clae21, AS63 and Clae23) (Fig. 3). The absence of the 1DS and 3DS sites in PI603249 was accompanied by lengthened chromosome 1D, a foreshortened chromosome 3D and a unique hybridization site on chromosome 3D (Fig. 5a), which might be indicative of a major structural alteration in the genome. In Clae21, both chromosomes 4D and 5D were unusual in length (Fig. 5b). All three Type I accessions lacking the 4DS site formed slender spikelets (Fig. 1), used as a diagnostic for var. meyeri, although Clae21 was classified as var. typica by its collector (Table 1). The sub-telomeric region of chromosome arm 6DS of the three Type I accessions PI431602, Clae26 and AS63, along with that of the Type S accession PI603227, harbored a further (CTT) 10 site (Fig. 3). The distribution of oligo-pTa-535 sites confirmed the closeness of the relationship between Types $S$ and I. In both the middle region of chromosome arm 2DS and the sub-telomeric region of chromosome arm 4DS, sites present in the Type $\mathrm{T}$ karyotype were missing in both Type $\mathrm{S}$ and $\mathrm{I}$, while the Type S-specific sites close to the chromosome arm 3DL telomere were also present in Type I (Fig. 4).
The weakly hybridizing sites lying on chromosome arm 5DL close to the centromere were present in both Type $\mathrm{S}$ and I accessions. Similarly, the chromosome arm 6DL region was more similar between Types $\mathrm{S}$ and I than between Types $S$ and T. Overall, the karyotypic analysis provided evidence that Type I accessions are genetically closer to Type $\mathrm{S}$ than to Type T.

The FISH karyotype of Ae. tauschii in relation to that of CS Probe $(\mathrm{CTT})_{10}$ hybridized to sites on chromosome arms 1DS and 2DS in the Type S and I accessions and also to the same location in CS (Fig. 3). However, neither the chromosome arm 3DS nor 4DS sites were present in CS, which was also a feature of the Type I accession Clae21, while AS63 and Clae23 lacked the 4DS site, but harbored the 3DS one. The $(\mathrm{CTT})_{10}$ sub-telomeric sites on 7DS were only present in the Type $S$ accession Clae16, Type I accession PI276985, and CS (Fig. 3). With respect to oligo-pTa-535, the karyotype of CS (as also that of the Type $\mathrm{S}$ and Type I accessions) lacked the sites at middle region on 2DS and the sub-telomeric region of 4DS, and shared a similar distribution of sites with the Types $\mathrm{S}$ and I accessions on chromosome arms 3DL, $5 \mathrm{DL}$ and $6 \mathrm{DL}$ and around the chromosome 5D centromere (Fig. 4).

\section{Discussion}

Although it was thought at one time that repetitive DNA had no function, it is now believed that it does play some role in chromosome organization and stabilization, mitosis and meiosis, and even gene regulation [38]. Both the amount and distribution of such
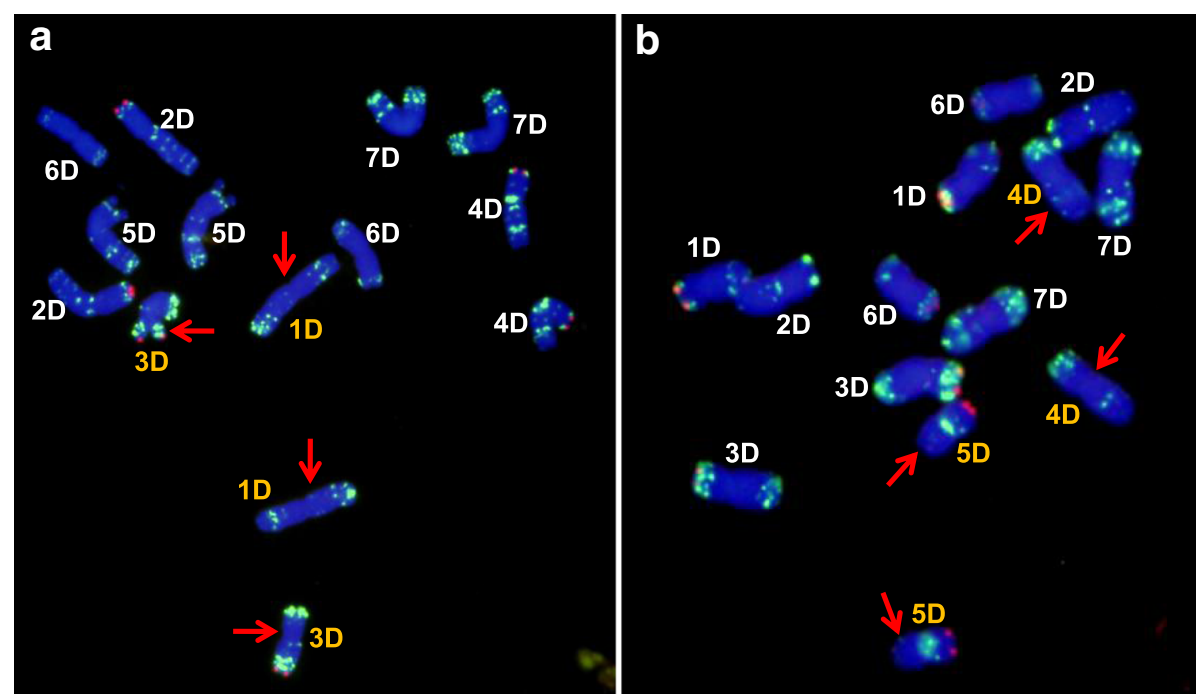

Fig. 5 Chromosome variants with oligo-pSc1 19.2 (red) and oligo-pTa-535 (green). a \#14 (PI603249) harbors a longer chromosome 1D and a shorter chromosome 3D; b \#22 (Clae 21) harbors a shorter chromosome 5D, and a version of chromosome 4D showing an unusual distribution of hybridization sites 
sequences act to drive evolution and speciation [39], so that their diversification has been used to assess genetic relatedness at both the species and the genome level $[40,41]$.

\section{Genome heterogeneity within Ae. tauschii}

FISH karyotyping based on two sequences (oligo-pTa535 and $(\mathrm{CTT})_{10}$ ) was able to reveal intraspecific differentiation within Ae. tauschii. Two distinct forms of the $\mathrm{D}$ genome were recognized from the karyotypic analysis of the 31 accessions (Figs. 3 and 4). One, present in nine accessions categorized as ssp. tauschii, is designated here $\mathrm{D}^{\mathrm{t}}$, and the other, present in the ssp. strangulata and morphologically intermediate forms, as $\mathrm{D}^{\mathrm{s}}$. Previous analyses based on marker genotype have also proposed the presence of two lineages [13-15]. Of the 31 accessions represented in the test germplasm set, 28 were also genotyped by Wang et al. 2013; a comparison of the outcomes shows the $\mathrm{D}^{\mathrm{t}}$ and $\mathrm{D}^{\mathrm{s}}$ designations to be fully congruent with, respectively, lineages L1 and L2 (Table 1). L1 members (seven accessions) all form spikes of the ssp. tauschii type (Type T). Meanwhile L2, according to the collectors' classification, consists of seven accessions designated as ssp. tauschii and 14 as ssp. strangulata [15]; a more exacting observation, however (see Fig. 1), has suggested that all of these seven supposed ssp. tauschii accessions, along with five of the 14 supposed ssp. strangulata accessions exhibit a spike morphology which better fits the intermediate type (Type I). The conclusion is that $\mathrm{L} 1 / \mathrm{D}^{\mathrm{t}}$ corresponds to ssp. tauschii and $\mathrm{L} 2 / \mathrm{D}^{\mathrm{s}}$ to either ssp. strangulata or the intermediate type (Table 1).

A re-consideration of intra-species taxa within Ae. tauschii Ae. tauschii has conventionally been sub-divided into the two subspecies tauschii and strangulata $[5,8]$, which leaves unclear the status of the morphologically intermediate forms. The present proposal is that membership of ssp. tauschii should be based on the formation of elongated cylindrical spikes and a low SI (Fig. 1), while the rest of the taxon, which includes both ssp. strangulata sensu stricto and intermediate forms, are classified as ssp. strangulata. Accordingly, ssp. tauschii var. meyeri, as an intermediate form, should be re-designated ssp. strangulata var. meyeri; this would fit with the genotypic data, which suggests that var. meyeri individuals are genetically closely related to ssp. strangulata [13, 15-18]. The suggested classification would result in a match between the botanically- and genetics-based categorizations, i.e. that ssp. tauschii becomes synonymous with lineage L1 $\left(D^{t}\right)$, and ssp. strangulata with L2 $\left(D^{s}\right)$.

\section{The diversification of the $D$ genome}

Of interest is the question as to how the $\mathrm{D}$ genome evolved the two distinct forms $\mathrm{D}^{\mathrm{t}}$ and $\mathrm{D}^{\mathrm{s}}$. Lineages L1 and L2 are recognizably different from one another, and virtually no intermediate forms are known [15]. On the basis of an analysis of non-coding chloroplast DNA sequences, it has been suggested that neither of the two subspecies could represent a progenitor of the other [42]. Here, the proposal is that the two subspecies originated independently, following a hybridization with a third species. According to Marcussen et al. [43], the bread wheat $\mathrm{A}$ and $\mathrm{B}$ genomes diverged from a common ancestor, and later combined to give rise to the $\mathrm{D}$ genome via homoploid hybrid speciation. If this evolutionary model is correct, it is possible that the two forms $\mathrm{D}^{\mathrm{t}}$ and $\mathrm{D}^{\mathrm{s}}$ evolved either from independent hybridization events or via segregation from a common progenitor hybrid.

An analysis based on single nucleotide polymorphisms has suggested that the donor of the bread wheat $\mathrm{D}$ genome was a member of the L2 lineage [15], to which the nine of the ten Type $\mathrm{S}$ accessions along belong (Table 1). The other five L2 members (PI276985, Clae26, AS63, Clae21 and Clae23) are all Type I, now re-designated as ssp. strangulata var. meyeri. One of these (Clae23) maps closest to the bread wheat D genome [15]. Given that the distribution of $(\mathrm{CTT})_{10}$ sites across the CS D genome more closely resembled that seen in Clae21, Clae23 and AS63 (Fig. 3), the conclusion is that the progenitor of the bread wheat $\mathrm{D}$ genome was likely a member of ssp. strangulata var. meyeri.

\section{Wheat $D$ genome genetic improvement}

Further genetic improvement is needed to match wheat production to an increasing global demand. Accessing novel genetic variation from wheat's D genome wild relatives has proved to be a highly successful strategy in recent years [44]. Probably very few Ae. tauschii individuals were involved in the original natural hybrids which were the progenitors of modern bread wheat, creating a major evolutionary bottleneck. Thus, of over $7000 \mathrm{D}$ genome single nucleotide polymorphism sites, about 99\% have been contributed by lineage L2 [15]. The implication is that a future priority should be to drive introgression from L1, using accessions such as AS60. The Chinese cultivar Shumai 969 released in 2013 was bred by using a synthetic hexaploid formed by crossing AS60 with Triticum turgidum [45]. It has rapidly become a leading cultivar in Sichuan Province, China, and demonstrates the potential of carriers of the $\mathrm{D}^{\mathrm{t}}$ genome for wheat improvement.

\section{Conclusions}

According to the reworking of the taxon, the bread wheat D genome was most probably donated by ssp. strangulata var. meyeri. Chromosomal differentiation reveals intraspecies taxon of Ae. tauschii. Ae. tauschii ssp. tauschii has more distant relationship with breed wheat than ssp. strangulata and can be used for breeding improving effectively. 


\section{Abbreviations}

Ae: Aegilops; CS: Chinese Spring; FISH: Fluorescence in situ hybridization; G: Glume width; R: Rachis segment width; SI: Subspecies index

\section{Acknowledgements}

We thank Dr. Mingcheng Luo (University of California, Davis) for the gift of accession AL8/78 and Robert Koebner (smartenglish2008@gmail.com) for revising the article.

\section{Funding}

This research was supported by the Chinese government National Key Research and Development Program (2016YFD0102000). The funding has no role in study design, data collection, data analysis, data interpretation, or writing the manuscript.

\section{Availability of data and materials}

The datasets supporting the conclusions of this article are included within the article and its additional files.

\section{Author' contributions}

D. L., L. Zhao., Y. Z., S. N. and M. H. planned and designed the research. L. Zhao, Y. Y., S. N. and Z. Y. performed experiments. J. W. and L. Zhang analyzed data. D. L., L. Zhao and M. H. wrote the manuscript. All authors have read and approved the manuscript.

\section{Ethics approval and consent to participate}

Plant materials with AS codes are from the Triticeae Research Institute, Sichuan Agricultural University, China; accessions with codes PI or Clae were from USDA-ARS, USA. Experimental research on plants complies with the guidelines of the People's Republic of China.

\section{Consent to publication}

Not applicable.

\section{Competing interests}

The authors declare that they have no competing interests.

\section{Publisher's Note}

Springer Nature remains neutral with regard to jurisdictional claims in published maps and institutional affiliations.

\section{Author details}

${ }^{1}$ Triticeae Research Institute, Sichuan Agricultural University, No. 211 Huiming Rd, Wenjiang District, Chengdu City, Sichuan province 611130, People's Republic of China. ${ }^{2}$ Key Laboratory of Crop Genetic Resources and Improvement, Ministry of Education, Sichuan Agricultural University, Yaan, Sichuan 625014, China.

Received: 6 June 2017 Accepted: 15 December 2017

Published online: 02 January 2018

\section{References}

1. van Slageren MW. Wild wheats: a monograph of Aegilops L. and Amblyopyrum (Jaub. \& Spach) Eig (Poaceae). Aleppo: Agricultural University, Wageningen; International Center for Agricultural Research in Dry Areas; 1994.

2. Kihara $\mathrm{H}$. Discovery of the DD-analyser, one of the ancestors of Triticum vulgare. Agric Hortic (Tokyo). 1944;19:889-90.

3. McFadden ES, Sears ER. The artificial synthesis of Triticum spelta. Rec Genet Soc of Am. 1944;13:26-7.

4. Kimber $G$, Yen Y. Analysis of pivotal-differential evolutionary patterns. Proc Natl Acad Sci U S A. 1988:85:9106-8.

5. Eig A. Monographish-kritische Ubersicht der Gattung Aegilops. In: Fedde F, editor. Repertorium specierum novarum regni vegetabilis. Dahlem bei Berlin, Germany: Verlag des Repertoriums; 1929. p. 1-228.

6. Kihara H, Tanaka M. Morphological and physiological variation among Aegilops squarossa strains collected in Pakistan, Afghanistan and Iran. Preslia. 1958:30:241-51.

7. Kihara H, Yamashita H, Tanaka M. Morhologic, physiological, genetical, and cytological studies in Aegilops and Triticum collected in Pakistan, Afghanistan, Iran. Results of the Kyoto University scientific expedition to the
Korakoram and Hidukush in 1955, vol. 1. In: Yamashita K, editor. Cultivated plants and their relatives. Kyoto: Kyoto University; 1965. p. 4-41.

8. Hammer K. Zur Taxonomie und Nomenklatur der Gattung Aegilops L. Feddes Repertorium. 1980;91:225-58.

9. Dudnikov AJ. Allozyme variation in Transcaucasian population of Aegilops squarrosa. Heredity. 1998:80:248-58.

10. Aghaei MJ, Mozafari J, Taleei AR, Naghavi MR, Omidi M. Distribution and diversity of Aegilops tauschii in Iran. Genet Resour Crop Ev. 2008:55:341-9.

11. Matsuoka Y, Nishioka E, Kawahara T, Takumi S. Genealogical analysis of subspecies divergence and spikelet-shape diversification in central Eurasian wild wheat Aegilops tauschii Coss. Plant Syst Evol. 2009;279:233-44.

12. Tanaka M. Geographical distribution of Aegilops species based on the collections at the plant Germplasm institute, Kyoto University. In: Sakamoto $\mathrm{S}$, editor. Proceedings of the 6th international wheat genetics symposium. Kyoto: Kyoto University; 1983. p. 1009-24.

13. Dvorak J, Luo MC, Yang ZL, Zhang HB. The structure of the Aegilops tauschi genepool and the evolution of hexaploid wheat. Theor Appl Genet. 1998; 97:657-70.

14. Mizuno N, Yamasaki M, Matsuoka Y, Kawahara T, Takumi S. Population structure of wild wheat D-genome progenitor Aegilops tauschii Coss:: implications for intraspecific lineage diversification and evolution of common wheat. Mol Ecol. 2010;19:999-1013.

15. Wang JR, Luo MC, Chen ZX, You FM, Wei YM, Zheng YL, Dvorak J. Aegilops tauschii single nucleotide polymorphisms shed light on the origins of wheat D-genome genetic diversity and pinpoint the geographic origin of hexaploid wheat. New Phytol. 2013;198:925-37.

16. Lubbers EL, Gill KS, Cox TS, Gill BS. Variation of molecular markers among geographically diverse accessions of Triticum tauschii. Genome. 1991;34:354-61.

17. Hedrick W. A new approach to measuring genetic similarity. Evolution. 1971; 25:276-80.

18. Lelley T, Stachel M, Grausgruber H, Vollmann J. Analysis of relationships between Aegilops tauschii and the D genome of wheat utilizing microsatellites. Genome. 2000;43:661-8

19. Rees H, Walters MR. Nuclear DNA and evolution of wheat. Heredity. 1965;20:73-82.

20. Arumuganathan K, Earle ED. Nuclear DNA content of some important plant species. Plant Mol Biol Rep. 1991;9:208-18.

21. Li W, Zhang P, Fellers JP, Friebe B, Gill BS. Sequence composition, organization, and evolution of the core Triticeae genome. Plant J. 2004:40:500-11.

22. Jia JZ, Zhao SC, Kong XY, Li YR, Zhao GY, He WM, Appels R, Pfeifer M, Tao Y, Zhang XY, Jing RL, Zhang C, Ma YZ, Gao LF, Gao C, Spannagl M, KFX M, Li D, Pan SK, Zheng FY, Hu Q, Xia XC, Li JW, Liang QS, Chen J, Wicker T, Gou CY, Kuang HH, He GY, Luo YD, Keller B, Xia QJ, Lu P, Wang JY, Zou HF, Zhang RZ, Xu JY, Gao JL, Middleton C, Quan ZW, Liu GM, Wang J, International Wheat Genome Sequencing Consortium, Yang H, Liu X, He ZH, Mao L, Wang J. Aegilops tauschii draft genome sequence reveals a gene repertoire for wheat adaptation. Nature. 2013;496:91-5

23. Gill BS, Friebe B, Endo TR. Standard karyotype and nomenclature system for description of chromosome bands and structural aberrations in wheat (Triticum aestivum). Genome. 1991:34:830-9.

24. Badaeva ED, Amosova AV, Muravenko OV, Samatadze TE, Chikida NN, Zelenin AV, Friebe B, Gill BS. Genome differentiation in Aegilops. 3. Evolution of the D-genome cluster. Plant Syst Evol. 2002;231:163-90.

25. Rayburn AL, Gill BS. Isolation of a D-genome specific repeated DNA sequence from Aegilops squarrosa. Plant Mol Biol Rep. 1986;4:102-9.

26. Nagaki K, Tsujimoto H, Isono K, Sasakuma T. Molecular characterization of a tandem repeat, Afa family, and its distribution among Triticeae. Genome. 1995:38:479-86.

27. Cuadrado A, Schwarzacher T, Jouve N. Identification of different chromatin classes in wheat using in situ hybridization with simple sequence repeat oligonucleotides. Theor Appl Genet. 2000;101:711-7.

28. Cuadrado A, Cardoso M, Jouve N. Increasing the physical markers of wheat chromosomes using SSRs as FISH probes. Genome. 2008;51:809-15.

29. Cuadrado A, Golczyk H, Jouve N. A novel, simple and rapid nondenaturing FISH (ND-FISH) technique for the detection of plant telomeres. Potential used and possible target structures detected. Chromosom Res. 2009;17:755-62.

30. Komuro S, Endo R, Shikata K, Kato A. Genomic and chromosomal distribution patterns of various repeated DNA sequences in wheat revealed by a fluorescence in situ hybridization procedure. Genome. 2013:56:131-7.

31. Tang ZX, Yang ZJ, Fu SL. Oligonucleotides replacing the roles of repetitive sequences pAs1, pSc119.2, pTa-535, pTa71, CCS1, and pAWRC.1 for FISH analysis. J Appl Genet. 2014;55:313-8 
32. Dudnikov AJ. Multivariate analysis of genetic variation in Aegilops tauschii from the world germplasm collection. Genet Resour Crop Ev. 2000;47:185-90.

33. Dudnikov AJ, Kawahara T. Aegilops tauschii genetic variation in Iran. Genet Resour Crop Ev. 2006;53:579-86.

34. Hao M, Luo JT, Yang M, Zhang LQ, Yan ZH, Yuan ZW, Zheng YL, Zhang HG, Liu DC. Comparison of homoeologous chromosome pairing between hybrids of wheat genotypes Chinese spring ph1b and Kaixian-luohanmai with rye. Genome. 2011;54:959-64.

35. Dennis ES, Gerlach WL, Peacock WJ. Identical polypyrimidine-polypurine satellite DNAs in wheat and barley. Heredity. 1980;44:349-66.

36. Pedersen C, Rasmussen SK, Linde-Laursen I. Genome and chromosome identification in cultivated barley and related species of the Triticeae (Poaceae) by in situ hybridization with the GAA-satellite sequence. Genome. 1996;39:93-104.

37. Zhao LB, Ning SZ, Yu JJ, Hao M, Zhang LQ, Yuan ZW, Zheng YL, Liu DC. Cytological identification of an Aegilops variabilis chromosome carrying stripe rust resistance in wheat. Breeding Sci. 2016;66:522-9.

38. Heslop-Harrison JS. Comparative genome organization in plants: from sequence and markers to chromatin and chromosomes. Plant Cell. 2000;12:617-36

39. Flavell R, O'Dell M, Smith D. Repeated sequence DNA comparisons between Triticum and Aegilops species. Heredity. 1979;42:309-22.

40. Dvorak J, Zhang HB. Reconstruction of the phylogeny of the genus Triticum from variation in repeated nucleotide sequences. Theor Appl Genet. 1992; 84:419-29.

41. Mehrotra S, Goyal V. Repetitive sequences in plant nuclear DNA: types, distribution, evolution and function. Genomics Proteomics Bioinformatics. 2014;12:164-71.

42. Dudnikov AJ. Chloroplast DNA non-coding sequences variation in Aegilops tauschii Coss.: evolutionary history of the species. Genet Resour Crop Ev. 2012;59:683-99.

43. Marcussen T, Sandve SR, Heier L, Spannagl M, Pfeifer M, The International Wheat Genome Sequencing Consortium, Jakobsen KS, Wulff BB, Steuernagel B, Mayer KF, Olsen OA. Ancient hybridizations among the ancestral genomes of bread wheat. Science. 2014:345:1250092

44. Dreisigacker S, Kishii M, Lage J, Warburton M. Use of synthetic hexaploid wheat to increase diversity for CIMMYT bread wheat improvement. Aust J Agric Res. 2008;59:413-20.

45. Liu DC, Hao M, Li AL, Zhang LQ, Zheng YL, Mao L. Allopolyploidy and interspecific hybridization for wheat improvement. In: Mason AS, editor. Polyploidy and hybridization for crop improvement. Boca Raton: CRC Press; 2016. p. 27-52.

\section{Submit your next manuscript to BioMed Central and we will help you at every step:}

- We accept pre-submission inquiries

- Our selector tool helps you to find the most relevant journal

- We provide round the clock customer support

- Convenient online submission

- Thorough peer review

- Inclusion in PubMed and all major indexing services

- Maximum visibility for your research

Submit your manuscript at www.biomedcentral.com/submit

C) Biomed Central 